GEOLOGICAL SURVEY CIRCULAR 82

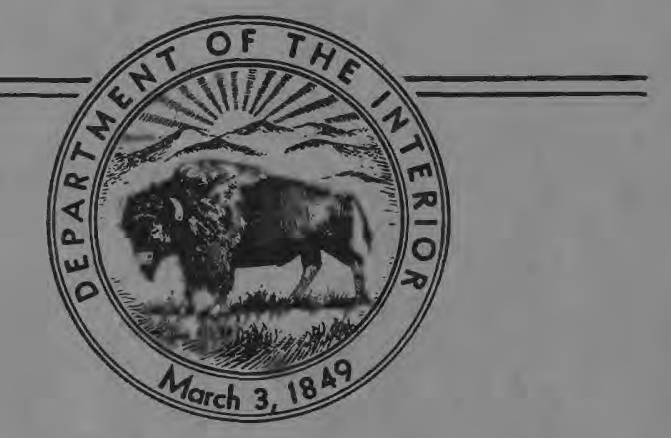

July 1950

\title{
THE TWINPLEX
}

A NEW STEREOPLOTTING INSTRUMENT

By Morris M. Thompson 


\section{UNITED STATES DEPARTMENT OF THE INTERIOR \\ Oscar L. Chapman, Secretary \\ GEOLOGICAL SURVEY \\ W. E. Wrather, Director}

WASHINGTON, D. C.

Free on application to the Geological Survey, Washington 25, D. C. 


\title{
THE TWINPLEX
}

\section{A NEW STEREOPLOTTING INSTRUMENT}

\author{
By Morris M. Thompson
}

\section{CONTENTS}

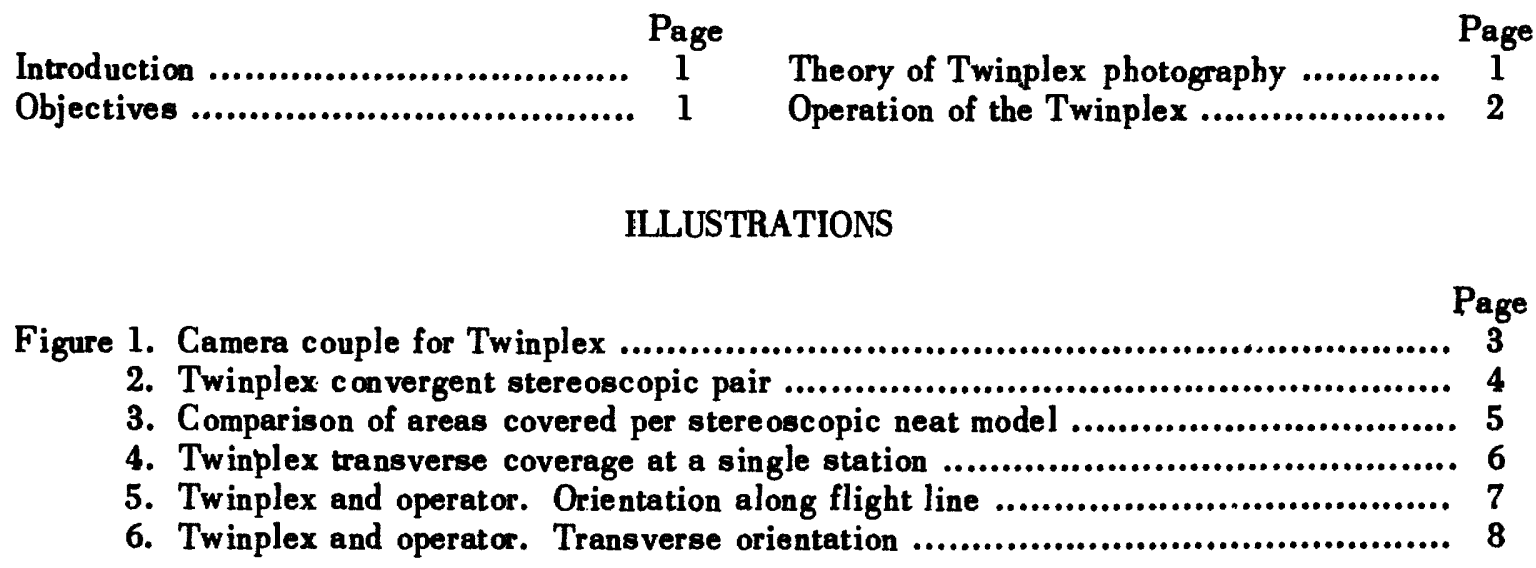




\section{INTRODUCTION}

During recent years, the technical procedures of topographic mapping have been profoundly altered by the use of aerial photographs as the basic source material for map compilation. An aerial photograph, however, does not in itself constitute a map. Because of variations in ground elevations, tilting of the camera, and other phenomena, the aerial photograph gives a distorted picture of the terrain; furthermore, a single aerial photograph affords no means of measuring variations in ground elevation. For converting the information contained in the photographs into accurate topographic maps, various plotting instruments have been developed. These instruments range from relatively simple devices, used for the production of maps of relatively low accuracy, to elaborate plotting machines designed for mapping to a high standard of precision. The plotting instruments that have been devised are, in general, increasingly complex as a higher degree of precision is attained. The Geological Survey has recently completed the prototype model of a new instrument of moderate complexity, called the "Twinplex," which embodies an unusual approach to the problems of precision and reconnaissance mapping.

The following exposition of the manner in which the Twinplex functions necessarily includes technical terminology that may be unfamiliar to persons who are not grounded in the science of photogrammetry. However, anyone who understands the functioning of the widely known Multiplex instrument should have no difficulty, in grasping the principles of the Twinplex.

\section{OBJECTIVES}

The Twinplex is a stereoplotting instrument that was conceived by Russell $\mathrm{K}$. Bean of the Geological Survey and developed under his direction, during the years following World War II, with three principal objectives:

1. Decreasing the over-all cost of precision mapping.

2. Increasing the accuracy of mapping operations.

3. Producing a versatile instrument suitable for precision mapping, reconnaissance mapping, and aerial triangulation.

\section{THEORY OF TWINPLEX PHOTOGRAPHY}

As a prerequisite to the utilization of the Twinplex, it is necessary to have photographs obtained with a special twin-camera arrangement consisting of a pair of wide-angle precision aerial cameras coupled rigidly together so that, assuming no tilt, their respective optical axes lie in a common vertical plane and form an angle of $20^{\circ}$ with a plumb line and $40^{\circ}$ with each other. (See fig. 1.) This gives a total angle of net coverage of $114^{\circ}$ in the plane containing the optical axes for a 6-inch focal length and 9-inch square format. The shutters are synchronized so that simultaneous exposures are made with both cameras of the coupled pair. The camera system may be oriented in two ways:

1. Along the flight line (that is, the vertical plane containing the optical axes also contains the flight line).

2. Transverse to the flight line (that is, the vertical plane containing the optical axes is normal to the flight line).

Orientation along the flight line gives the convergent low-oblique photography that is the basis of precision mapping with the Twinplex. For a series of exposure stations, one of the two exposures at station 1 will be convergent with one of the two exposures at station 2 . Likewise, the second exposure at station 2 will be convergent with one of the two exposures at station 3 . It is these convergent pairs of exposures from successive stations that overlap to form the stereoscopic models (fig. 2). The shape of the ground area covered by each photograph is trapezoidal, and the stereoscopic overlap forms a hexagon with the photographs overlapping each other 100 percent in the direction of the flight line. From the geometry of the oblique system, the base-height ratio is 1.23 and the width-height ratio is 1.27 . The comparable values for vertical photography are 0.65 for base-height ratio and 1.15 for widthheight ratio. Because of the increased baseheight ratio, a favorable $\mathrm{C}$ factor (ratio of flight height to the least contour interval that may be plotted accurately) is obtained in the Twinplex. This figure has tentatively been set at 1,000. Assuming that a 20-foot contour interval is desired, the flight height will be 20,000 feet, and an area comparable to a 7.5minute quadrangle can be compiled with three 
Twinplex models as against twenty models in present wide-angle Multiplex systems. The economies resulting from the reduction in the number of photographs required, in the number of model set-ups required, and above all in the number of control points required are readily apparent. (See fig. 3.)

Orientation transverse to the flight line (fig. 4) is suitable for reconnaissance mapping at larger contour intervals. For this arrangement, the base-height ratio is 0.63 and the widthheight ratio is 2.31 , making possible the coverage of an area with a greatly reduced number of flight lines. The $\mathrm{C}$ factor assumes a value of about 600 . However, by flying at 30,000 feet, only one flight and five models are required to compile a full 15-minute quadrangle, assuming a contour interval of 50 feet or larger. Each model, in transverse orientation, consists of all four exposures taken at two successive exposure stations (two at each station). A half model is formed by the overlap of the right-hand exposure of station 1 with the right-hand exposure of station 2. Another half model is formed by the overlap of the left-hand exposure of station 1 with the left-hand exposure of station 2 .

\section{OPERATION OF THE TWINPLEX}

The Twinplex is essentially a doubleprojection type of stereoplotting instrument utilizing diapositives printed without rectification from the oblique photography described above. It is arranged so that it can utilize either orientation of the photography--along the flight line (fig. 5) or transverse (fig. 6). However, instead of the series of single projectors found in conventional double-projection instruments, the Twinplex has a series of sets of twin projectors. In each set, the two projectors are locked together so that they move as a unit. The two diapositives used in a set of twin projectors correspond respectively to the two exposures made at one camera station. (These exposures do not make a stereoscopic model; each must be paired with an exposure from an adjacent camera station in order to obtain stereoscopic overlap). Physical límitations prevent the simultaneous orientation of both projectors of a set, as obviously the lenses of both projectors cannot occupy the same point in space at the same time. Provision is made to allow each of the two projectors to be brought, in turn, into position for forming a model with the appropriate projector of an adjacent set. Whether the orientation is transverse or along the flight line, only one projector of each set of twin projectors is in use at any one time, but the set of projectors is so mounted that once either of the projectors has been oriented, the other can be brought into orientation by swinging it into a previously calibrated second position. Thus, for photography along the flight line, when compilation of the model formed by the convergent pair from statious 1 and 2 has been completed, the twin set of projectors at station 2 is swung into its second position. In this position, the projector that was not one of the convergent pair forming the first model is now oriented so that a correctly oriented second model can be formed by bringing the convergent projector at station 3 into relative orientation. For transverse photography, when compilation of the half model formed by the right-hand exposures of stations 1 and 2 is complete, both projector sets are swung into the second position. In this position, the half model formed by the left-hand exposures of stations 1 and 2 is automatically oriented.

Aerial triangulation can be accomplished when the camera system is oriented either along the flight line or transverse to it. More accurate triangulation can be achieved with orientation along the flight line because of the increased $\mathrm{C}$ factor. On the other hand, triangulation, with transverse orientation has the advantage that the control points at each end of the bridge can be spaced twice as far apart in a direction normal to the flight lines.

The prototype model of the Twinplex, the only one in existence at this time, was completed in December 1949 and exhibited at the January 1950 meeting of the American Society of Photogrammetry. The Geological Survey is currently engaged in an experimental mapping project to determine the performance characteristics of the instrument. A full appraisal of its qualities must necessarily await completion of this test project; however, preliminary tests indicate that the apparatus will, in practice, substantiate its theoretical capabilities. 


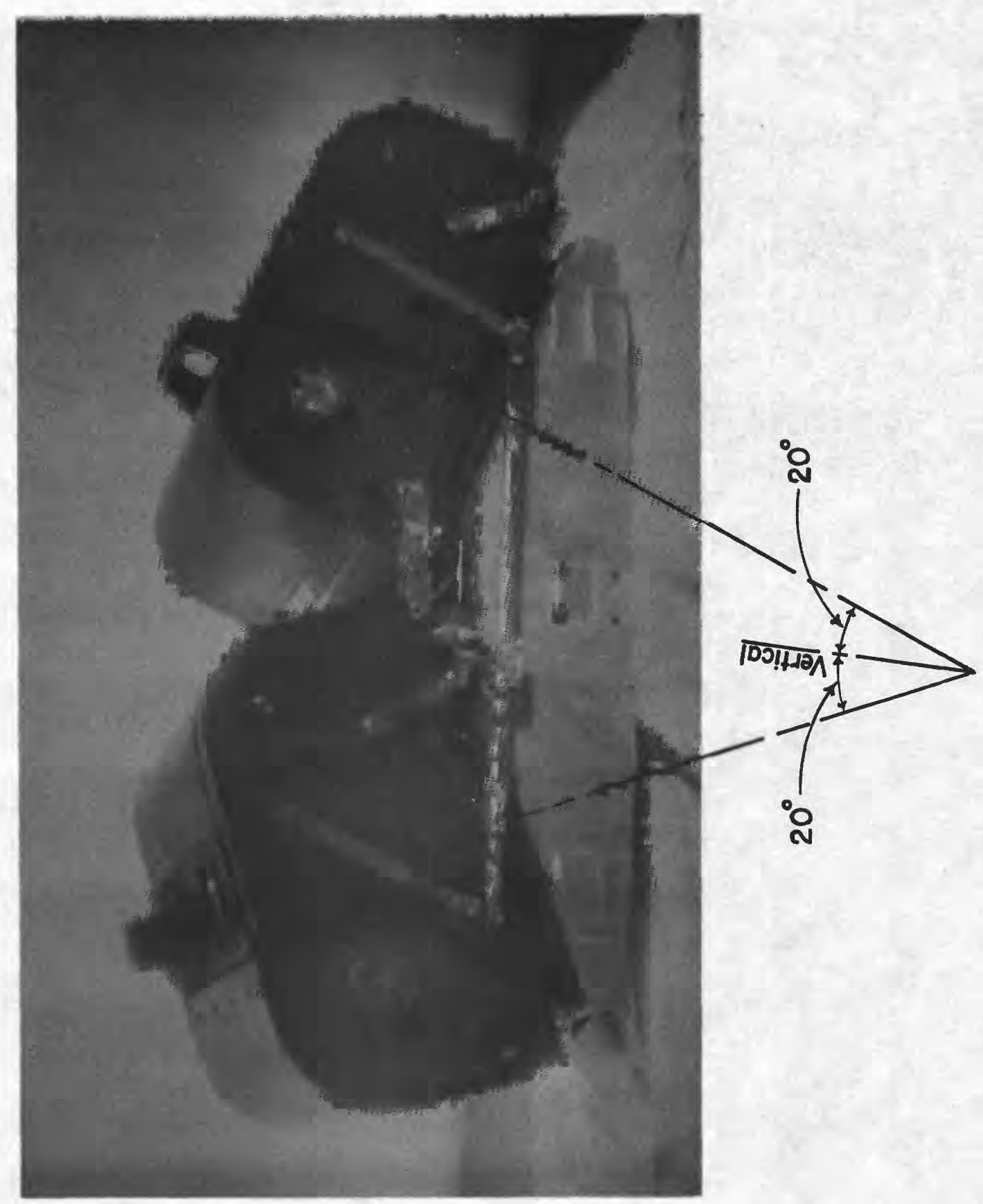

 


\section{For $H=12,000$, area of neat model $=8.1 \mathrm{sq} \cdot \mathrm{mi}$.}

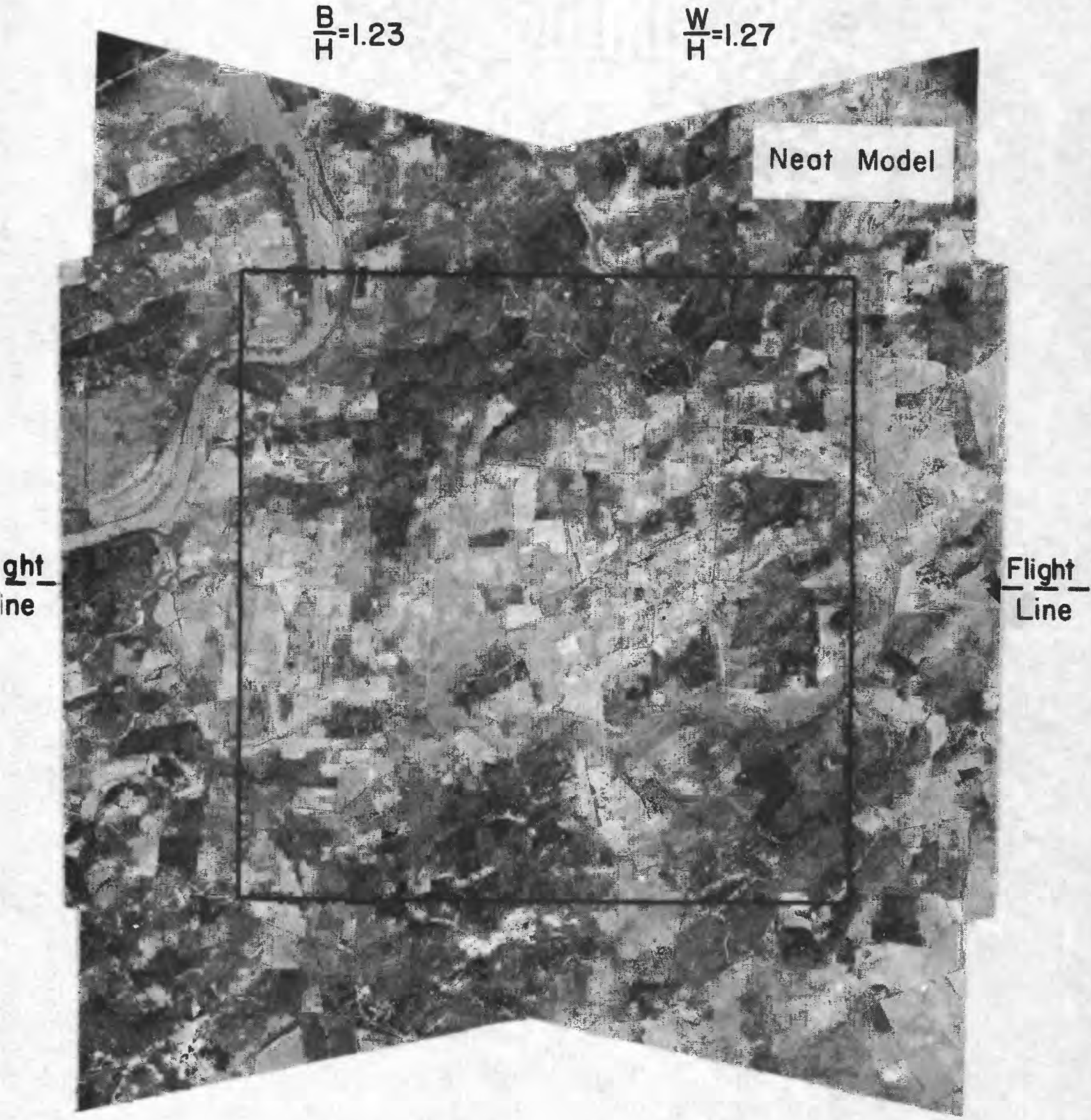

Fig. 2 Twinplex convergent stereoscopic pair. (Photographs rectified to demonstrate coverage of the overlapping exposures from two successive stations. The divergent exposures are not shown.) 
COMPARISON OF WORKING NEAT MODEL AREAS

FOR

$20 \mathrm{FT}$. CONTOURING

WITH

WIDE ANGLE PHOTOGRAPHY

$\mathrm{C}=1,000$; CONVERGENT LOW OBLIQUES

22.4 SQ.MI.

TWINPLEX (EXPECTED)

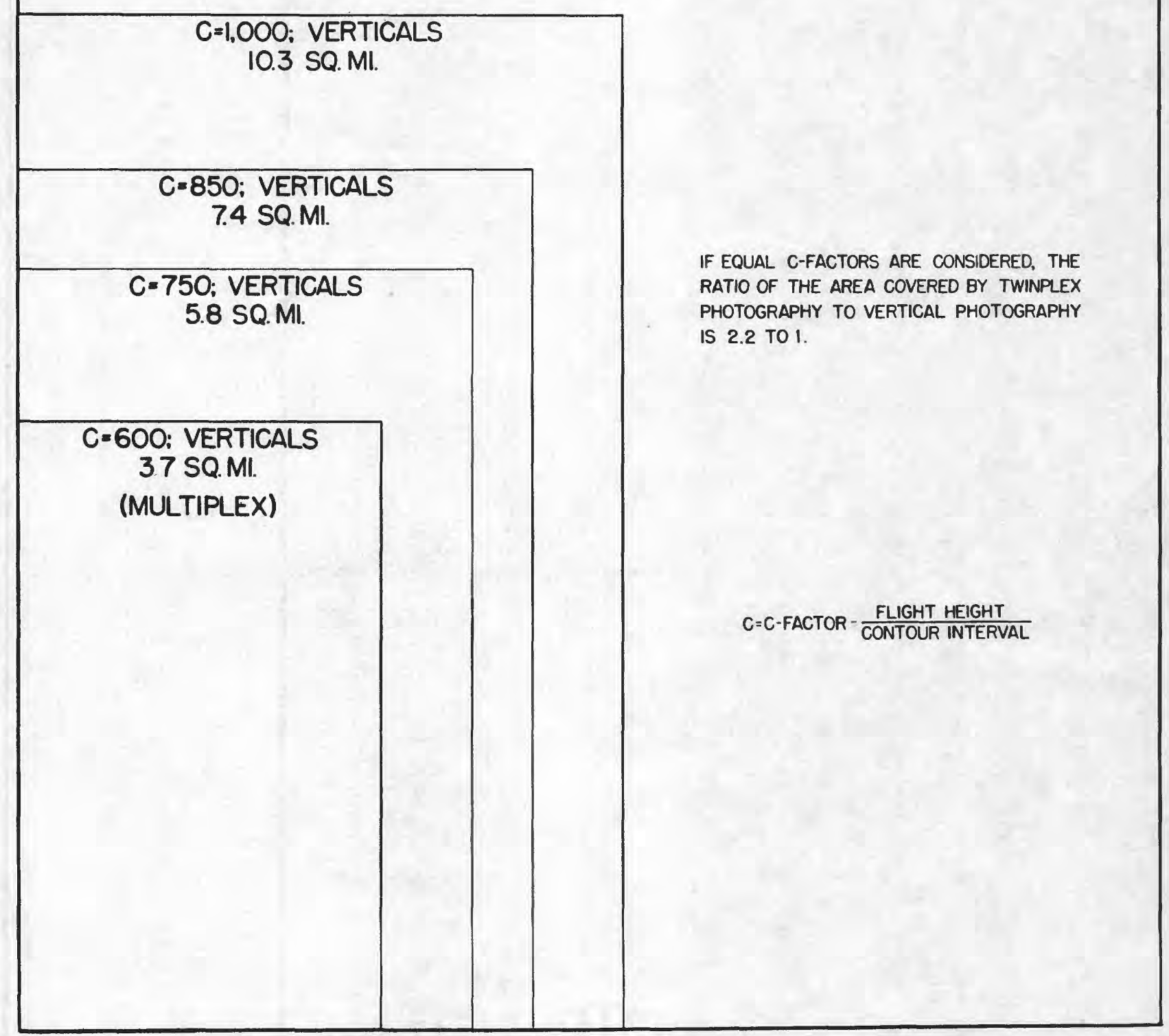

Fig. 3 Comparison of areas covered per stereos opic neat model. 


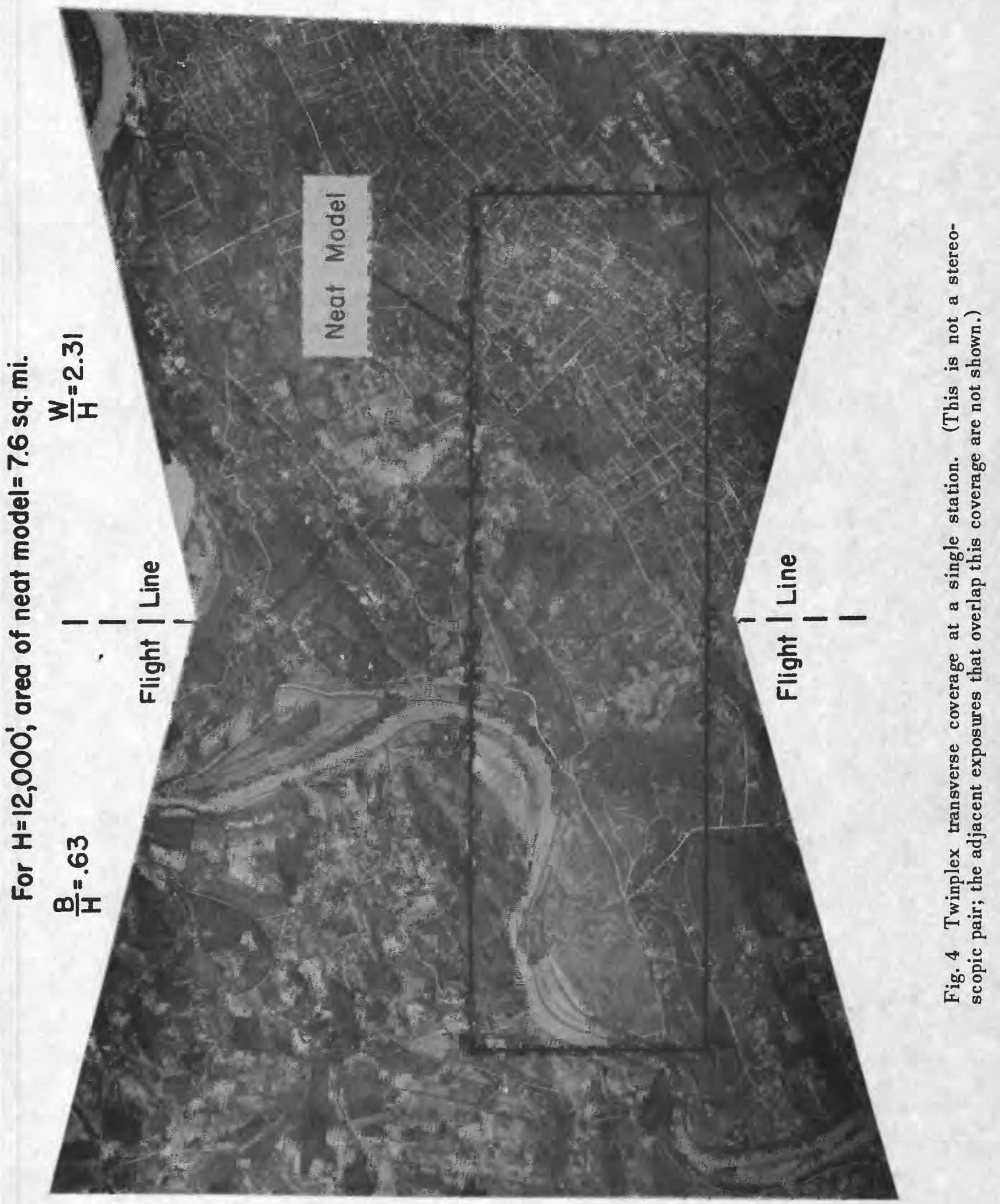




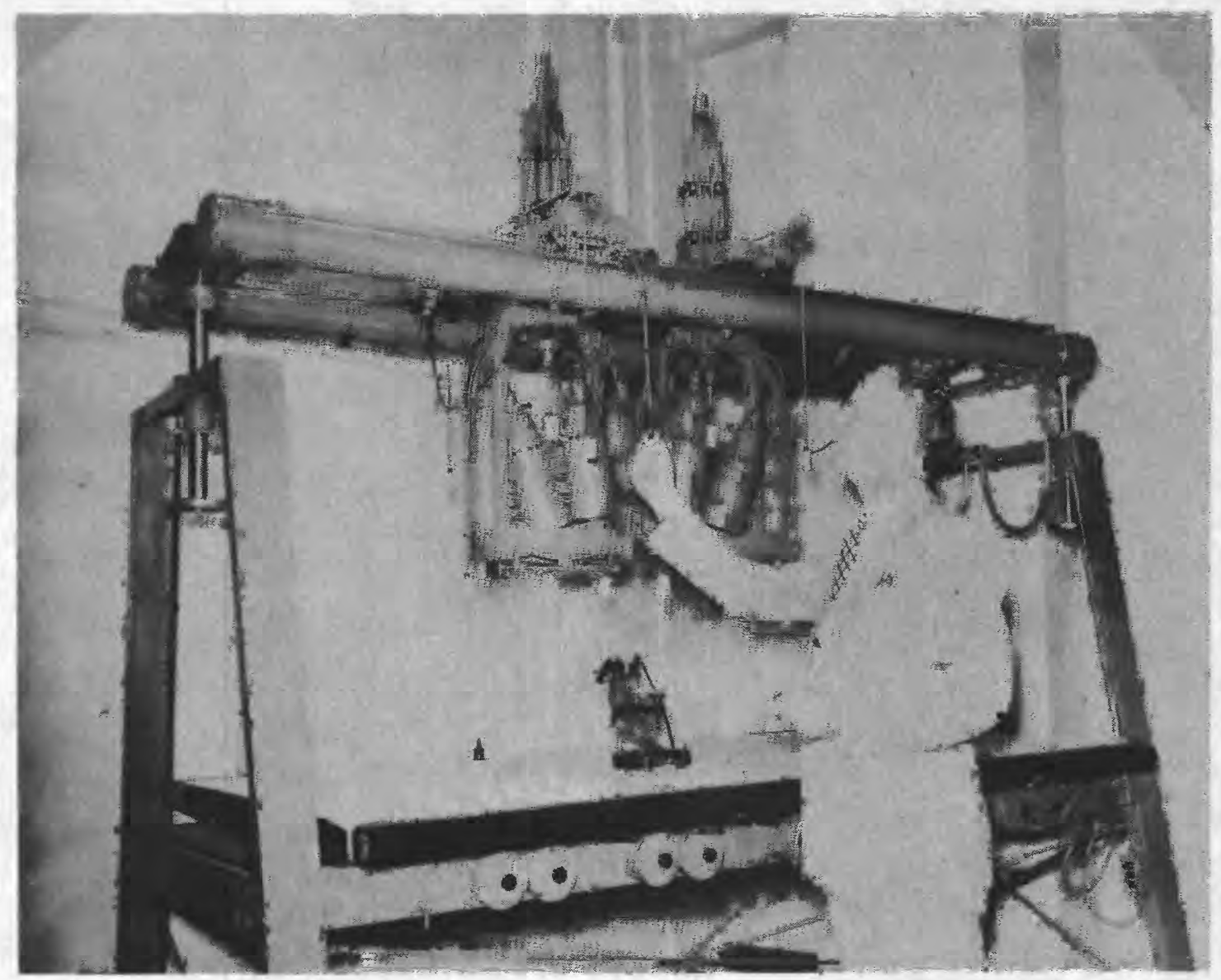

Fig. 5 Twinplex and operator. Orientation along flight line. 


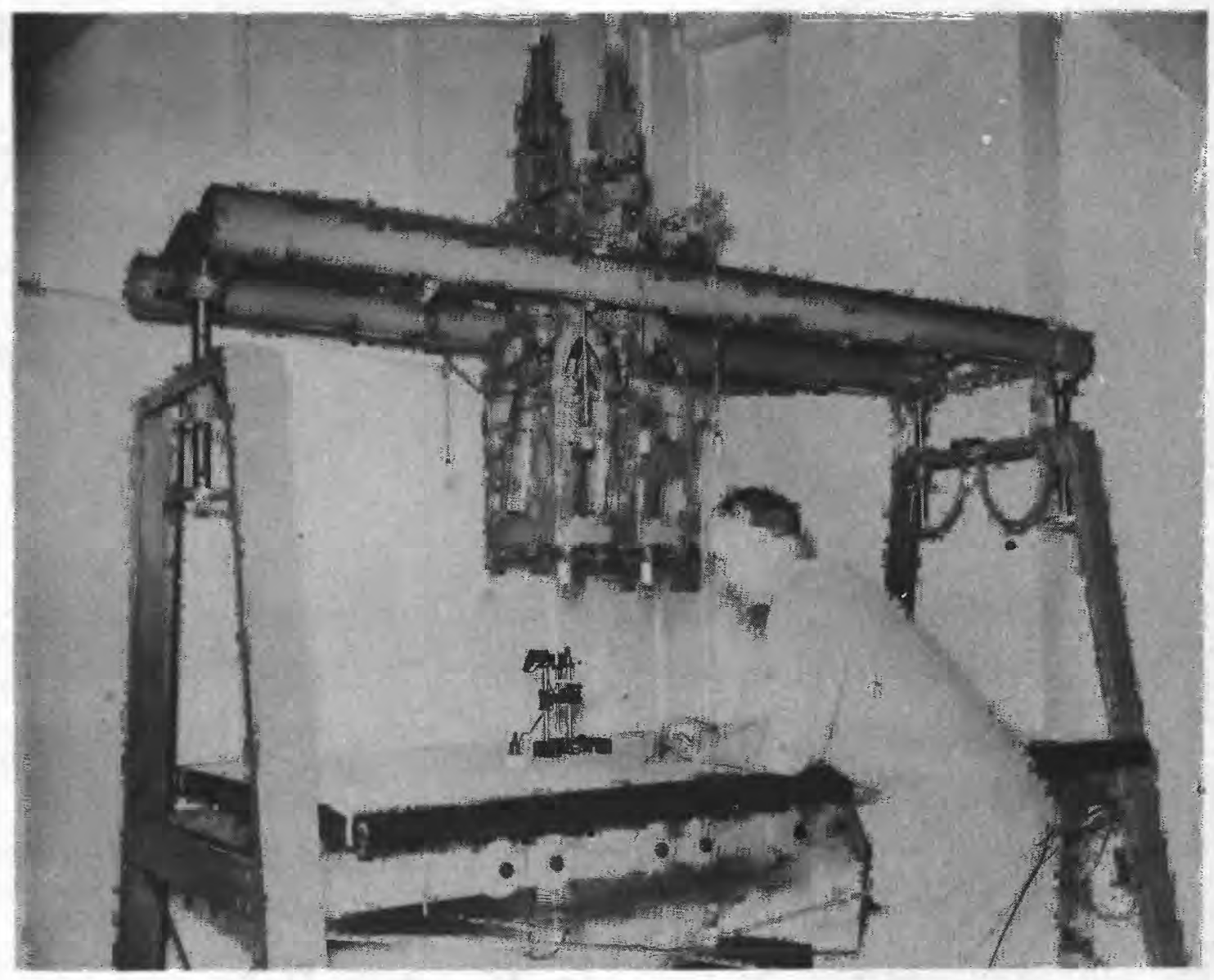

Fig. 6 Twinplex and operator. Transverse orientation. 